\title{
Preparation and Characterization of the Electrospun Alginate Nanofibers
}

\author{
Mohammad Forhad Hossain ${ }^{1}$ (), Mustafijur Rahman 2 (i) \\ ${ }^{1}$ Faculty of Textile Chemical Engineering, Bangladesh University of Textiles, Dhaka, Bangladesh \\ ${ }^{2}$ Department of Dyes \& Chemical Engineering, Bangladesh University of Textiles, Dhaka, Bangladesh \\ Email: forhadbd77@gmail.com, musta130@gmail.com
}

How to cite this paper: Hossain, M.F. and Rahman, M. (2021) Preparation and Characterization of the Electrospun Alginate Nanofibers. Journal of Textile Science and Technology, 7, 91-100.

https://doi.org/10.4236/jtst.2021.72008

Received: April 28, 2021

Accepted: May 23, 2021

Published: May 26, 2021

Copyright $\odot 2021$ by author(s) and Scientific Research Publishing Inc. This work is licensed under the Creative Commons Attribution International License (CC BY 4.0).

http://creativecommons.org/licenses/by/4.0/

\begin{abstract}
Due to some intrinsic functional behavior of alginate, many potential applications in the healthcare industry especially in wound care sector are observed. Many researches have been carried out to develop potential biomedical biocompatible products in different forms from alginate fibres. Alginate nanofibres were prepared from sodium alginate polymer with the presence of poly(ethylene oxide) (PEO), a small amount of Triton $\times 100$ surfactant. A homogeneous spinning solution was prepared for producing $\mathrm{Na}$-alginate/PEO nanofibers in electrospinning device. Nanofibres were produced by electrospinning from 70:30 and 80:20 Na-alginate/PEO of $4 \%$ solution. After a series of trials, the electrospinning parameters were optimized at $16 \mathrm{~cm}$ working distance, $0.4 \mathrm{~mL} / \mathrm{h}$ flow rate and $10.5 \mathrm{kV}$ applied voltage. The results show that the $4 \mathrm{wt} \%$ of $70: 30 \mathrm{Na}$-alginate/PEO solution with $0.5 \mathrm{wt} \%$ Triton $\times 100$ surfactant yielded smooth and stable electrospinning. The surface morphology of the fibres was investigated using Scanning Electron Microscope (SEM) and found the uniform fibres with an average diameter of $124 \mathrm{~nm}$ containing few thick or spindle-like fibres. FTIR investigation identified the chemical structure and molecular changes that occurred in the fibers.
\end{abstract}

\section{Keywords}

Alginate, Electrospinning, Nanofibres, Characterization, Morphology

\section{Introduction}

Nanofibrous materials have potential applications in filtration, catalysis, and sensing including sophisticated biomedical applications such as tissue engineering, drug delivery, artificial blood vessels, and wound dressing [1] [2] [3]. The chemical, mechanical, structural, and biological properties of nanofibres from functional polymers can be optimized to obtain maximum functional benefits. Algi- 
nate, a non-toxic natural polysaccharide, is one of the most popular biopolymers used to produce wound dressing materials [4] [5]. It can absorb large amount of wound fluid and form gel-like substance that maintains "moist healing" microenvironment in the wound. When a calcium alginate fibre comes in contact with wound fluid an ion exchange reaction occurs between calcium ion $\left(\mathrm{Ca}^{2+}\right)$ of calcium alginate fibre and sodium ion $\left(\mathrm{Na}^{+}\right)$of wound fluid. As a result, $\mathrm{Ca}^{2+}$ is released to the wound which acts as a haemostatic agent to facilitate wound healing [6]. Moreover, calcium alginate turns to sodium alginate gel which provides "moist healing" microenvironment.

Alginate fibres are conventionally produced using wet-spinning technique. In this process, a homogeneous $\mathrm{Na}$-alginate viscous solution is prepared and then extruded through a fine spinneret. The extruded fibres are collected into a bath containing calcium chloride $\left(\mathrm{CaCl}_{2}\right)$ solution to obtain insoluble calcium alginate fibres [5] [6]. The diameter of the fibres produced in this technique varies from few $\mu \mathrm{m}$ to few hundred $\mu \mathrm{m}$. Due to its ability to absorb high volumes of wound fluid, and its role in supporting growing and spreading of epithelium in the wound, nanofibrous alginate dressings have attracted keen interest from researchers [2] [7] [8].

However, sodium alginate is not suitable for electrospinning which has been the most widely used by many researchers [9] [10] [11] [12]. This is because Na-alginate is a polyelectrolyte biopolymer that contains polyanions like chitosan [13]. The polyanions of Na-alginate molecule repulse each other and hinder molecular chain entanglement. Moreover, Na-alginate especially with high guluronic acid (G) content, which may turn into a gel easily, becomes too viscous for electrospinning at slightly higher concentration. These problems can be overcome by adding a suitable copolymer and a small amount of surfactant to the $\mathrm{Na}$-alginate solution. Research found that the hydrogen bonds between the polyelectrolytes and poly(ethylene oxide) (PEO) polymer favor producing electrospun alginate nanofibers [14] [15]. A specified proportion of Na-alginate and PEO along with a small amount of surfactant reduces the surface tension and viscosity which improves the electrospinnability and alginate content of the spinning solution [1] [16]. As a result, the fibre forming ability of alginate/PEO solution would increase more, even at higher alginate content in the solution [17].

Several studies have shown that 70:30 Na-alginate/PEO of $4 \mathrm{wt} \%$ polymer concentration yielded smooth nanofibres [2] [14] [16]. Thus, in the present study, 70:30 and 80:20 Na-alginate/PEO of $4 \mathrm{wt} \%$ solutions were used for electrospinning experiments to investigate the surface morphology of the nanofibres. This study comprises the systematic approach of electrospinning experiments and characterization of the fibres.

\section{Materials and Methods}

\subsection{Materials}

Na-alginate (high G) powder was received from ConvaTec UK, PEO powder 
$\left(M_{W}=900,000\right)$ and Triton $\times 100$ were purchased from Sigma-Aldrich. The syringe $(10 \mathrm{~mL}, \mathrm{BD}$ Plastipak) and needle $(18 \mathrm{G})$ were supplied by Beckton Dickinson Plastipak. All chemicals were used without further purification.

\section{Preparation of Spinning Solution}

Specific amount of Na-alginate powder $(0.7 \mathrm{~g})$ and PEO $(0.3 \mathrm{~g})$ were added with $23.875 \mathrm{~g}$ distilled water in a $60 \mathrm{~mL}$ bottle by using a precision electronic balance to prepare $4 \mathrm{wt} \%$ of 70:30 Na-alginate/PEO spinning solution. A $0.5 \mathrm{wt} \%$ of Triton $\times 100(0.125 \mathrm{~g})$ surfactant was mixed to the spinning solution to improve the homogeneity and electrospinnability of the solution. Then the solution was stirred using a magnetic stirrer for overnight at room temperature (around $20^{\circ} \mathrm{C}$ ) to obtain a uniform spinning solution Similarly, 80:20 Na-alginate/PEO of $4 \mathrm{wt} \%$ solution was also prepared for electrospinning trials [17].

\subsection{Methods}

\subsubsection{Instrumental Setup and Electrospinning}

The electrospinning process was employed to make nanofibres from Na-alginate/ PEO. The electrospinning device (Figure 1) consists of a pump (feed rate: 0.12 $\mathrm{mL} / \mathrm{h}-120 \mathrm{~mL} / \mathrm{h}$; manufacturer: Kd Scientific, Holliston, MA), a high voltage (DC voltage) power supply (positive power supply: $0-30 \mathrm{kV} \mathrm{DC}$; current: maximum $660 \mu \mathrm{A}$; manufacturer: Ormond beach FL32174), a grounded metal collector (height $220 \mathrm{~mm}$ and width $150 \mathrm{~mm}$ ) and a syringe (10-mL Beckton Dickinson; manufacturer: Beckton Dickinson Plastipak) with a blunt tip needle (18 G; $1.2 \mathrm{~mm}$ diameter $\times 40 \mathrm{~mm}$ length; manufacturer: Beckton Dickinson Plastipak). The syringe, filled with spinning solution was fixed to the pump. The collector was placed opposite of the syringe needle at a predetermined distance from the needle tip. This is called working distance or air-gap distance. The syringe type (10-mL Beckton Dickinson), feed rate and volume of solution were set by using the control board. An aluminium foil with appropriate size was fixed on the collector metal plate by using adhesive tape. When all the parameters were set, the pump was started to allow to form a small droplet at the tip of the needle. Once the droplet of spinning solution appeared on the tip of the needle, an electric potential was applied by switching on the voltage supply. The experiments were carried out at $12-20 \mathrm{~cm}$ working distance, $0.3-1.0 \mathrm{~mL} / \mathrm{h}$

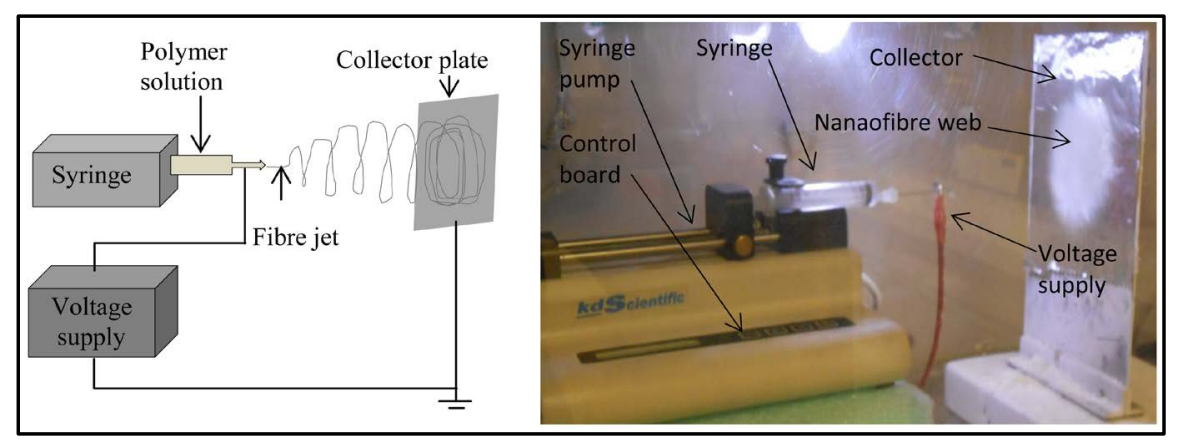

Figure 1. Schematic of an electrospinning and laboratory setup. 
feed rate, and $9-12 \mathrm{kV}$ applied voltage to obtain smooth fibres. The continuous electrospun fibres were deposited on the foil, making a circular-shaped fibre collection zone (web). After allowing for a specific period of time of electrospinning, the foil with deposited fibres was collected for drying 24 hours at room temperature to remove the residual solvents. For ensuring the safety, the electrospinning rig was placed in a glass compartment, consisting of a safety micro-switch device which disconnects the voltage supply when the door is open. Moreover, an earthing rod was also mounted to neutralize the residual static charge in the device. All of the electrospinning experiments were carried out at room temperature.

\subsubsection{Characterization of the Nanofibres}

\section{1) Surface morphology}

The surface morphology of the yielded electrospun nanofibres were examined by Field Emission Gun Scanning Electron Microscope (SEM) (PHILIPS XL30 FEG-SEM). The electrospun fibre webs on the collector were cut into $0.5 \mathrm{~cm} \times$ $0.5 \mathrm{~cm}$ size and adhered on a specimen stub by carbon tape necessary for SEM purpose. The specimens were then coated with carbon using gatan Precision Etching Coating System (model: 682). The images were taken at 1000x, 2000x, $10,000 \times$ and 20,000 $\times$ magnification. The SEM operating parameters were set at 6 $\mathrm{kV}$ accelerating voltage and spot size 3 . The fibre diameters were manually measured by using the line-drawing feature of Image $\mathrm{J}$ software from 50 randomly selected fibres from the $10,000 \times$ and $20,000 \times$ magnification images at 3 different places. The Image J line drawing feature represents the line length in pixels. The pixels were converted to standard units of length measurements using the SEM image scale bar.

\section{2) FTIR analysis}

The chemical structure and molecular interaction between alginate and PEO were observed using Fourier Transform Infrared Spectroscopy (FTIR) (model: NICOLET5700 FT-IR; manufacturer: Thermo Electron Corporation). A typical FTIR provides the frequencies on basis of absorption of infrared light related to respective chemical bonds. The infrared spectra of absorption mode of the samples were obtained from FTIR spectrometer which was connected with a computer. The FTIR records were taken at room temperature between $4000 \mathrm{~cm}^{-1}$ and $400 \mathrm{~cm}^{-1}$ spectral ranges with 32 scans and a resolution of $4 \mathrm{~cm}^{-1}$. The test record was taken from the three different places of the samples.

\section{3) Solubility of the nanofibres}

The solubility of as-spun Na-alginate/PEO nanofibres was tested in accordance with BS EN 13726-1:2002 section 3.7 dispersion and solubility of hydrogel dressings. In the procedure, the samples of $2 \mathrm{~cm} \times 2 \mathrm{~cm}$ size were submerged in $20 \mathrm{~mL}$ distilled water in a petri-dish and shacked for 2 minutes to allow dissolution, then left for $120 \pm 10 \mathrm{~min}$ at room temperature. The fibre content was observed visually (bare eye) to assess the solubility of the nanofibres. This test was carried out at $37^{\circ} \mathrm{C}$ and repeated on three samples. 


\section{Results and Discussion}

\subsection{Optimization of the Na-Alginate/PEO Electrospinning Process}

Table 1 shows the summary of the electrospinning trials of $4 \mathrm{wt} \%$ of $70: 30$ $\mathrm{Na}$-alginate/PEO and the effects of process parameters. During electrospinning, it was observed that feed rate and applied voltage influenced the process most. At a constant working distance and applied voltage, a higher feed rate yielded frequent droplets at the tip of the needle. However, lower applied voltage at constant working distance and feed rate also produced droplets. After a series of trials, the process parameters were optimized at $16 \mathrm{~cm}$ working distance, $0.4 \mathrm{~mL} / \mathrm{h}$ flow rate and $10.5 \mathrm{kV}$ applied voltage, which were consistent with previous studies [1] [16] [18]. However, the $4 \mathrm{wt} \%$ of 80:20 Na-alginate/PEO solution generated frequent droplets. This may have happened due to aggregation of higher content of $\mathrm{Na}$-alginate in the spinning solution.

\subsection{Morphological Characteristics of the Na-Alginate/PEO Nanofibres}

Figure 2 shows the scanning electron microscope (SEM) images of nanofibres obtained from 70:30 and 80:20 Na-alginate/PEO of $4 \%$ solution. The results show that the $4 \mathrm{wt} \%$ of $70: 30$ of $\mathrm{Na}$-alginate/PEO solution with $0.5 \mathrm{wt} \%$ Triton $\times 100$ surfactant yielded smooth fibres having an average diameter of $124 \mathrm{~nm}$ with some thick or spindle-like fibres. However, the 80:20 Na-alginate/PEO solution produced beaded fibres with beads-on-string structure. Thick beads and fibre breaks were formed from 80:20 Na-alginate/PEO solution due to frequent

Table 1. Summary of electrospinning trials.

\begin{tabular}{|c|c|c|c|c|}
\hline $\begin{array}{l}\text { Experiment } \\
\text { no. }\end{array}$ & $\begin{array}{l}\text { Working } \\
\text { distance }\end{array}$ & $\begin{array}{l}\text { Feed } \\
\text { rate }\end{array}$ & $\begin{array}{l}\text { Applied } \\
\text { voltage }\end{array}$ & Observations \\
\hline 1 & $16 \mathrm{~cm}$ & $0.5 \mathrm{~mL} / \mathrm{h}$ & $9 \mathrm{kV}$ & $\begin{array}{l}\text { Stable jet, uniform deposition but } \\
\text { slowly formed droplet }\end{array}$ \\
\hline 2 & $16 \mathrm{~cm}$ & $0.5 \mathrm{~mL} / \mathrm{h}$ & $10 \mathrm{kV}$ & $\begin{array}{l}\text { Stable jet, uniform deposition but } \\
\text { slowly formed droplet }\end{array}$ \\
\hline 3 & $16 \mathrm{~cm}$ & $0.5 \mathrm{~mL} / \mathrm{h}$ & $11 \mathrm{kV}$ & $\begin{array}{l}\text { Stable jet, uniform deposition but } \\
\text { slowly produced droplets }\end{array}$ \\
\hline 4 & $16 \mathrm{~cm}$ & $0.4 \mathrm{~mL} / \mathrm{h}$ & $9 \mathrm{kV}$ & $\begin{array}{l}\text { Stable jet and uniform deposition but } \\
\text { slowly formed droplets }\end{array}$ \\
\hline 5 & $16 \mathrm{~cm}$ & $0.4 \mathrm{~mL} / \mathrm{h}$ & $10 \mathrm{kV}$ & Stable jet and uniform deposition \\
\hline 6 & $16 \mathrm{~cm}$ & $0.4 \mathrm{~mL} / \mathrm{h}$ & $11 \mathrm{kV}$ & Stable jet and uniform deposition \\
\hline 7 & $16 \mathrm{~cm}$ & $0.3 \mathrm{~mL} / \mathrm{h}$ & $9 \mathrm{kV}$ & $\begin{array}{l}\text { Stable jet and uniform deposition but } \\
\text { slowly formed droplets }\end{array}$ \\
\hline 8 & $16 \mathrm{~cm}$ & $0.3 \mathrm{~mL} / \mathrm{h}$ & $10 \mathrm{kV}$ & Stable jet and uniform deposition \\
\hline 9 & $16 \mathrm{~cm}$ & $0.3 \mathrm{~mL} / \mathrm{h}$ & $11 \mathrm{kV}$ & Stable jet, uniform deposition \\
\hline 10 & $16 \mathrm{~cm}$ & $0.4 \mathrm{~mL} / \mathrm{h}$ & $10.5 \mathrm{kV}$ & $\begin{array}{l}\text { Stable jet, uniform deposition } \\
\text { (optimized process parameters) }\end{array}$ \\
\hline
\end{tabular}




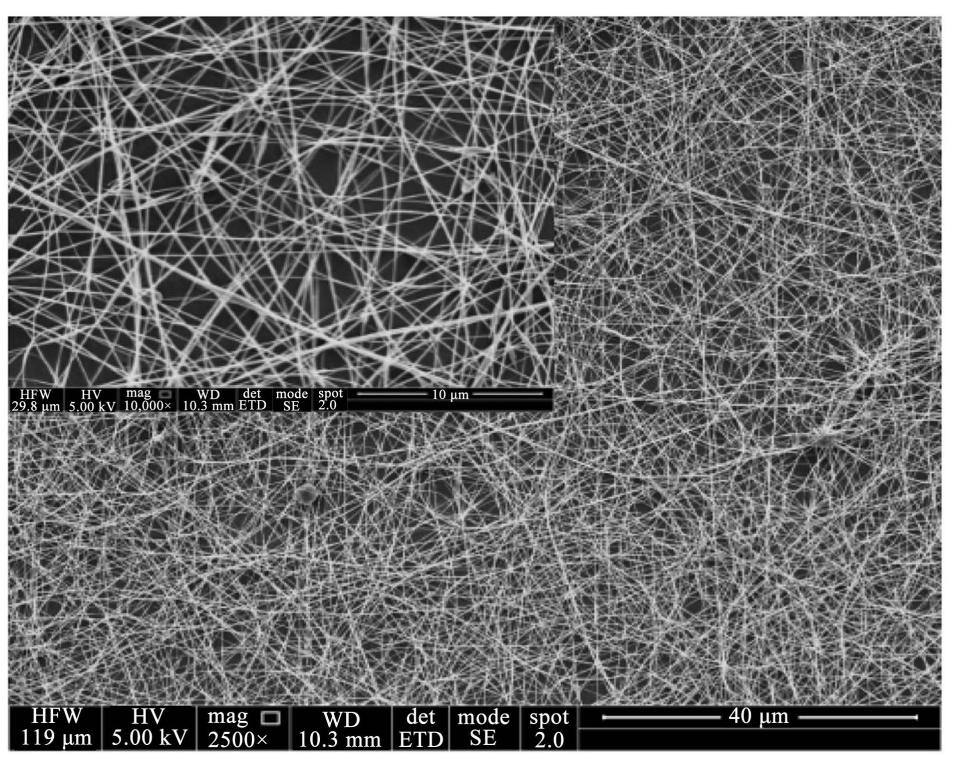

(a)

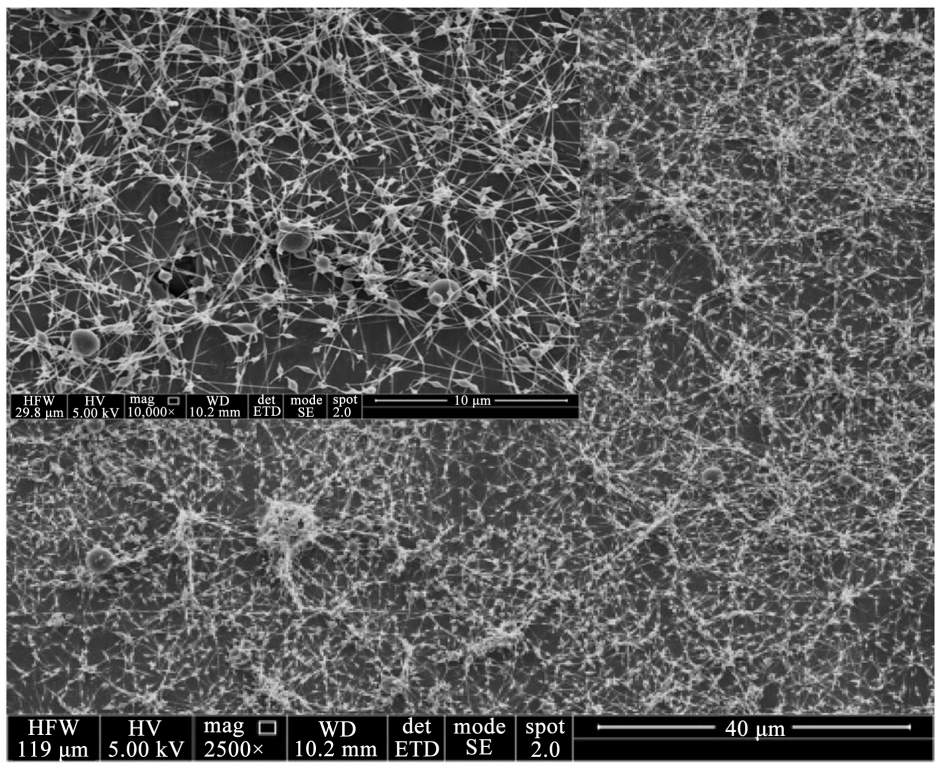

(b)

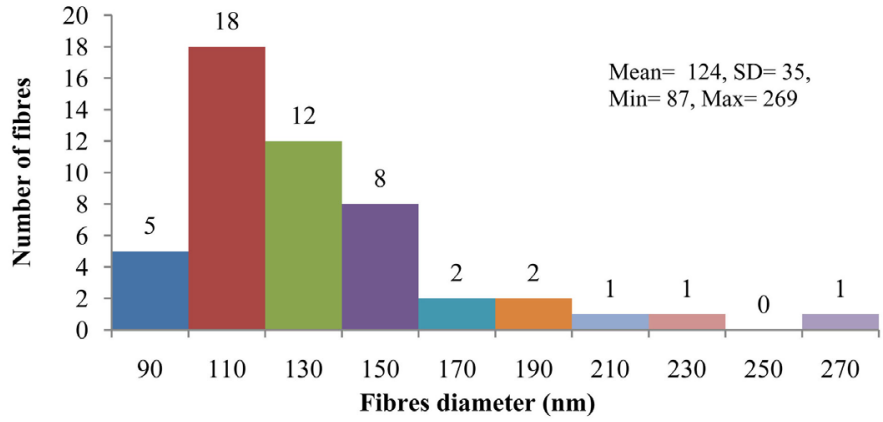

(c)

Figure 2. SEM images $2000 \times$ (inset $10,000 \times$ ) of 4.0 wt\% of 70:30 (a) and 80:20 (b) $\mathrm{Na}$-alginate/PEO nanofibres; and fibre size distribution (c) of 70:30 Na-alginate/PEO nanofibres. 
droplet formation at the tip of the needle. This may have happened due to aggregation of the solution which leads to incomplete stretching of the fibre jet. Similar findings were observed in previous studies [2] [16] [19] where the bead formation increased with increasing proportion of non-spinnable sodium alginate in sodium alginate/PEO blend.

The Figure 2(c) depicted the distribution of the fibres based on the diameter. The results found that the diameter of the fibres lies between $90 \mathrm{~nm}$ and $150 \mathrm{~nm}$ of $86 \%$ of fibres. However, the diameter of the $60 \%$ of the fibres found $110 \mathrm{~nm}$ to $130 \mathrm{~nm}$ on which highest $36 \%$ at $110 \mathrm{~nm}$. The findings indicate the uniformity of the nanofibers produced from 70:30 Na-alginate/PEO.

\subsection{FTIR Analysis}

Fourier Transform Infrared Spectroscopy (FTIR) was used to characterize the produced Na-alginate/PEO nanofibes. Figure 3 represents the FTIR spectra of pure $\mathrm{PEO}, \mathrm{Na}$-alginate and $\mathrm{Na}$-alginate/PEO nanofibers in order within 4000 $400 \mathrm{~cm}^{-1}$ (a) and $2000-1000 \mathrm{~cm}^{-1}$ (b) spectral range. The Figure depicted the spectral peak variation between $\mathrm{PEO}$ nanofibres, pure $\mathrm{Na}$-alginate, and Na-alginate/PEO

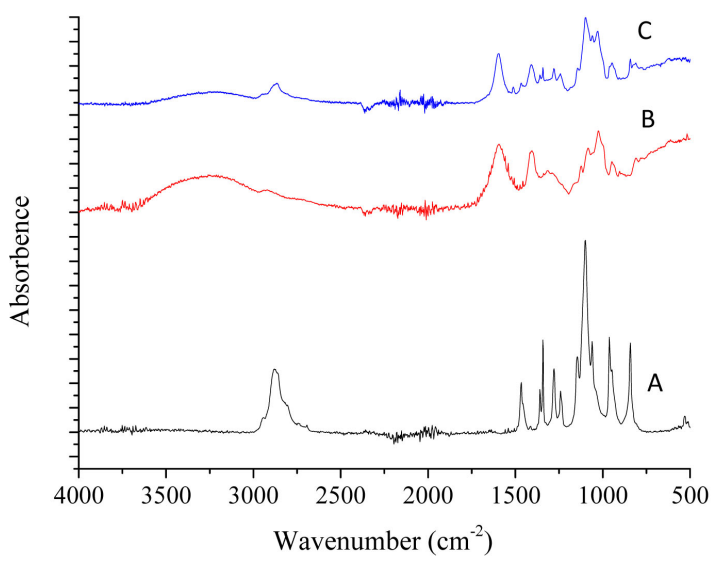

(a)

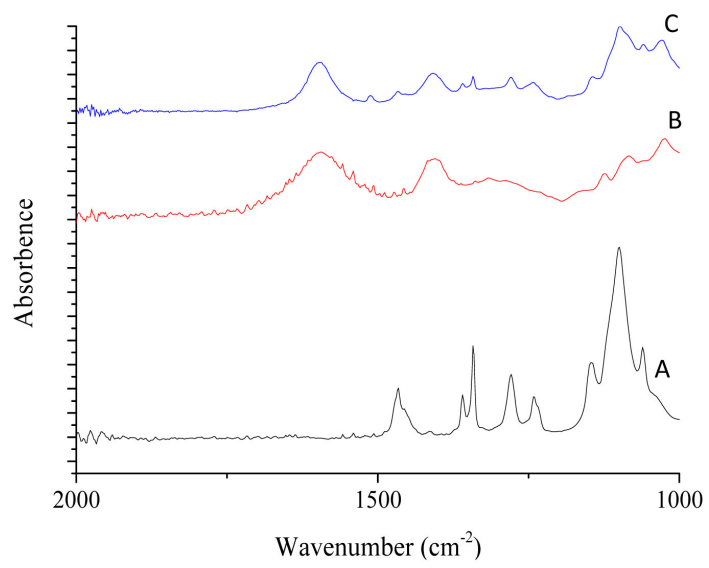

(b)

Figure 3. FTIR spectra of PEO nanofibres (A) Na-alginate (B), and Na-alginate/PEO nanofibres $(\mathrm{C})$. 
nanofibres. The chemical interaction between $\mathrm{PEO}$ and $\mathrm{Na}$-alginate was confirmed by the FTIR findings. Due to chemical interaction, PEO showed some prominent spectrum at $1100 \mathrm{~cm}^{-1}$ and $843 \mathrm{~cm}^{-1}$ for C-O-C (ether group) asymmetric stretch and bending vibrations. $\mathrm{Na}$-alginate showed some characteristic bands at $3336 \mathrm{~cm}^{-1}$ for -OH (hydroxyl group) stretching, $1593 \mathrm{~cm}^{-1}$ for COO-(carboxylate group) symmetrical stretching and $1410 \mathrm{~cm}^{-1}$ for COO-symmetrical stretching. The asymmetrical absorption band for $\mathrm{C}-\mathrm{O}-\mathrm{C}$ of $\mathrm{PEO}$ was shifted from $1100 \mathrm{~cm}^{-1}$ to $1095 \mathrm{~cm}^{-1}$ in Na-alginate/PEO nanofibre. The asymmetrical band of $\mathrm{Na}$-alginate for $\mathrm{COO}^{-}$was shifted to $1612 \mathrm{~cm}^{-1}$ in Na-alginate/PEO from 1593 $\mathrm{cm}^{-1}$. Furthermore, the hydrogen bonds formed between ether oxygen of PEO and hydroxyl group of Na-alginate in the Na-alginate/PEO nanofibres, which is confirmed by the stretching band of Na-alginate/PEO at $3336 \mathrm{~cm}^{-1}$. These chemi$\mathrm{cal}$ interactions reduce the repulsive force between polyanionic sodium alginate molecules, which ultimately positively influence the electrospinning. Hence, the findings from the FTIR analysis are similar to the previous studies [17] [19] [20] [21].

\subsection{Solubility of the Na-Alginate/PEO Nanofibres}

The solubility of the Na-alginate/PEO nanofibres in water was assessed according to BS EN 13726-1:2002 Section 3.7 dispersion and solubility of hydrogel dressings. It was found that the fibres had good solubility, and dissolved completely. In contact with water, the nanofibres were dissolved within 2 - 3 minute. This is expected because both sodium alginate and PEO are water soluble [6]. However, the produced $\mathrm{Na}$-alginate nanofibers need to be treated with calcium chloride $\left(\mathrm{CaCl}_{2}\right)$ to obtain insoluble alginate nanofibers [14]. Further study can be conducted to produce insoluble Ca-alginate fibres.

\section{Conclusion}

The study described the experimental procedure of electrospinning process of $\mathrm{Na}$-alginate/PEO and optimized the process parameters to obtain uniform smooth nanofibres. Bead-free uniform fibres with an average diameter of about $124 \mathrm{~nm}$ were obtained from $4.0 \mathrm{wt} \%$ of 70:30 Na-alginate/PEO compositions. The diameter of the $60 \%$ of fibres lies between $110 \mathrm{~nm}$ and $130 \mathrm{~nm}$, and $86 \%$ lies between $90 \mathrm{~nm}$ and $150 \mathrm{~nm}$. SEM analysis expressed the morphological characteristics and FTIR identified the chemical structure and molecular change that occurred in the produced nanofibers. Then, these fibres can be deposited on other substrates to form composite materials such as wound dressing. However, these nanofibers cannot retain the structure when it comes in contact with water or wet substance. The nanofibres need to be converted to insoluble by cross-linking with calcium salt. Hence, the yielded nanofibres can be modified by chemical treatment with calcium chloride $\left(\mathrm{CaCl}_{2}\right)$ to make them insoluble.

\section{Conflicts of Interest}

The authors declare no conflicts of interest regarding the publication of this paper. 


\section{References}

[1] Bhattarai, N., Li, Z., Edmondson, D. and Zhang, M. (2006) Alginate-Based Nanofibrous Scaffolds: Structural, Mechanical, and Biological Properties. Advanced Materials, 18, 1463-1467. https://doi.org/10.1002/adma.200502537

[2] Kong, Q., Yu, Z., Ji, Q. and Xia, Y. (2009) Electrospinning of Sodium Alginate with Poly(ethylene oxide), Gelatin and Nanometer Silver Colloid. Materials Science Forum, 610-613, 1188-1191. https://doi.org/10.4028/www.scientific.net/MSF.610-613.1188

[3] Doshi, J. and Reneker, D.H. (1993) Electrospinning Process and Applications of Electrospun Fibers. Conference Record, Industry Applications Society, IEEE-IAS Annual Meeting, Vol. 3, 1698-1703.

[4] Varaprasad, K., Jayaramudu, T., Kanikireddy, V., Toro, C. and Sadiku, E.R. (2020) Alginate-Based Composite Materials for Wound Dressing Application: A Mini Review. Carbohydrate Polymers, 236, Article ID: 116025. https://doi.org/10.1016/j.carbpol.2020.116025

[5] Yeung, R.A. and Kennedy, R.A. (2019) A Comparison of Selected Physico-Chemical Properties of Calcium Alginate Fibers Produced Using Two Different Types of Sodium Alginate. The Journal of the Mechanical Behavior of Biomedical Materials, 90 , 155-164. https://doi.org/10.1016/j.jmbbm.2018.10.011

[6] Qin, Y. (2008) Alginate Fibres: An Overview of the Production Processes and Applications in Wound Management. Polymer International, 57, 171-180.

https://doi.org/10.1002/pi.2296

[7] Coşkun, G., Karaca, E., Ozyurtlu, M., Özbek, S., Yermezler, A. and Çavuşoğlu, I. (2014) Histological Evaluation of Wound Healing Performance of Electrospun Poly(vinyl alcohol)/Sodium Alginate as Wound Dressing in Vivo. Bio-Medical Materials and Engineering, 24, 1527-1536. https://doi.org/10.3233/BME-130956

[8] Bhattarai, N. and Zhang, M. (2007) Controlled Synthesis and Structural Stability of Alginate-Based Nanofibers. Nanotechnology, 18, Article ID: 455601. https://doi.org/10.1088/0957-4484/18/45/455601

[9] Tucker, N., Hofman, K., Stanger, J., Staiger, M., Hamid, N.A. and Torres, P.L. (2011) The History of the Science and Technology of Electrospinning from 1600 to 1995. Journal of Engineered Fibers and Fabrics, 7, 63-73. https://doi.org/10.1177/155892501200702S10

[10] Xue, J., Wu, T., Dai, Y. and Xia, Y. (2019) Electrospinning and Electrospun Nanofibers: Methods, Materials, and Applications. Chemical Reviews, 119, 5298-5415. https://doi.org/10.1021/acs.chemrev.8b00593

[11] Kleivaite, V. and Milašius, R. (2018) Electrospinning-100 Years of Investigations and Still Open Questions of Web Structure Estimation. Autex Research Journal, 18, 398-404. https://doi.org/10.1515/aut-2018-0021

[12] Islam, M.S., Ang, B.C., Andriyana, A. and Afifi, A.M. (2019) A Review on Fabrication of Nanofibers via Electrospinning and Their Applications. SN Applied Sciences, 1, 1-16. https://doi.org/10.1007/s42452-019-1288-4

[13] Li, L. and Lo Hsieh, Y. (2006) Chitosan Bicomponent Nanofibers and Nanoporous Fibers. Carbohydrate Research, 341, 374-381. https://doi.org/10.1016/j.carres.2005.11.028

[14] Mirtič, J., Balažic, H., Zupančič, Š. and Kristl, J. (2019) Effect of Solution Composition Variables on Electrospun Alginate Nanofibers: Response Surface Analysis. Po- 
lymers (Basel), 11, 692. https://doi.org/10.3390/polym11040692

[15] Mincheva, R., Manolova, N., Paneva, D. and Rashkov, I. (2005) Preparation of Polyelectrolyte-Containing Nanofibers by Electrospinning in the Presence of a NonIonogenic Water-Soluble Polymer. Journal of Bioactive and Compatible Polymers, 20, 419-435. https://doi.org/10.1177/0883911505057447

[16] Saquing, C.D., et al. (2013) Alginate-Polyethylene Oxide Blend Nanofibers and the Role of the Carrier Polymer in Electrospinning. Industrial \& Engineering Chemistry Research, 52, 8692-8704. https://doi.org/10.1021/ie302385b

[17] Hossain, M.F., Rahman, M. and Nur, M.G. (2017) Ageing Effects of Na-Alginate/ PEO Spinning Solution on Electrospinnability and Morphology of Nanofibres. European Scientific Journal, 13, 56.

https://doi.org/10.19044/esj.2017.v13n9p56

[18] Hu, C., Gong, R.H. and Zhou, F.L. (2015) Electrospun Sodium Alginate/Polyethylene Oxide Fibers and Nanocoated Yarns. International Journal of Polymer Science, 2015, Article ID: 126041. https://doi.org/10.1155/2015/126041

[19] Lu, J.W., Zhu, Y.L., Guo, Z.X., Hu, P. and Yu, J. (2006) Electrospinning of Sodium Alginate with Poly(ethylene oxide). Polymer (Guildf.), 47, 8026-8031. https://doi.org/10.1016/j.polymer.2006.09.027

[20] Nie, H., et al. (2009) Effect of Poly(ethylene oxide) with Different Molecular Weights on the Electrospinnability of Sodium Alginate. Polymer (Guildf.), 50, 4926-4934. https://doi.org/10.1016/j.polymer.2009.07.043

[21] Jeong, S.I., Krebs, M.D., Bonino, C.A., Khan, S.A. and Alsberg, E. (2010) Electrospun Alginate Nanofibers with Controlled Cell Adhesion for Tissue Engineering. Macromolecular Bioscience, 10, 934-943.

https://doi.org/10.1002/mabi.201000046 